\title{
Investigation of Dosimetric Parameters of HDR Cobalt-60 after-loading Brachytherapy Source using Monte Carlo Fluka Code
}

Mahdi Sadeghi ${ }^{1 *}$, Arghavan Davoudi², Mitra Athari allaf ${ }^{2}$ and Ali Jafari ${ }^{3}$

${ }^{1}$ Department of Medical physics, School of Medicine, Iran University of Medical Science, P.O. Box: 14155-6183, Tehran, Iran

${ }^{2}$ Department of Medical Radiation Engineering, Science and Research Branch, Islamic Azad

${ }^{3}$ Department of Physics, IRIB University, Tehran, Iran

\begin{abstract}
The purpose of this article is to calculate TG-43 dosimetric parameters for high-dose-rate BEBIG ${ }^{\mathrm{TM}}$ model of the ${ }^{60} \mathrm{Co}$ after-loading brachytherapy source in several phantoms including, water, polystyrene, PMMA and RW1 using Monte Carlo Fluka code. Cobalt-60 can be used as an alternativeradio-isotopeto iridium- 192 for high-doserate brachytherapy treatment of a vast majority of cancers such as Lung, Cervix, malignancies. In addition, TG-43 protocol is presented by American Association of Physicists in Medicine (AAPM) to calculate dosimetric parameters of brachytherapy sources. The estimated dose rate constant in water is $1.0936 \frac{c G y}{h . U}$, intensity of air-Kermais $2.9429 \times 10^{-7} \frac{\mathrm{cGy} \cdot \mathrm{cm}^{2}}{h . B q}$ and 2D anisotropy function is in the range of 0.5 to $10 \mathrm{~cm}$ and angels change between 0 to 90 degrees. Consequently, the obtained results by the Fluka code were compared with those that were calculated by using MCNP and GEANT code. The comparison in this article has demonstrated a relatively good and acceptable similarity between these three codes. Overall, the Fluka code can be used to obtain dosimetric parameters in highdose-rate brachytherapy sources.
\end{abstract}

Keywords: Brachytherapy; Co-60 source; High-dose-rate; Fluka code; Monte Carlo Code

\section{Introduction}

Cobalt-60 is a synthetic radioactive isotope of cobalt with a halflife of 5.2714 years $\left(\mathrm{E}_{\gamma 1}=1.33 \mathrm{MeV}, \mathrm{I}_{\gamma 1}=99.99 \% ; \mathrm{E}_{\gamma 2}=1.17 \mathrm{MeV}\right.$, $\left.\mathrm{I}_{\gamma 2}=99.97 \%\right)$. It is produced artificially by neutron activation of the isotope ${ }^{59} \mathrm{Co}$. Corresponding to its half-life the radioactivity of one gram of ${ }^{60} \mathrm{Co}$ is about 50 curies. As cobalt-60 decays, 3 negative Beta, 6 Gamma and $15 \mathrm{X}$ radiation will be produced [1].

High-dose-rate after loading brachytherapy has been demonstrated as a successful method in treatment of cancers such as prostate, cervix, internal uterus, breast, skin, lung, esophagus, head and neck malignancies [1]. The optimal goal of radiotherapy is to expose radiation to the malignant cells with as little risk as possible to the normal cells, thus preserving normal organs function [2].

In addition, dosimetric calculations by modeling brachytherapy sources in the water phantom should be performed to fulfill the requirements according to American Association of Physicists in Medicine (AAPM) recommendations before the clinical use of new brachytherapy sources [3,4] Previously, American Association of Physicists in Medicine (AAPM) presented a protocol called TG-43 which offered formulation of dosage calculation and collection of data for dosimetric parameters of brachytherapy sources [5-13]. This protocol was revised in 2004 and its new edition was published as TG-43U1 [5]. Therefore, to meet the requirements of the protocol, dosimetric parameters of these sources need to be measured and calculated precisely. According to the updated TG -43 protocol, two methods need to be used in order to calculate the dosages around he radioactive sources. The first method is Monte Carlo simulation and the second one is completely experimental.

In this study, the simulation method for estimation of dosimetry parameters of the ${ }^{60} \mathrm{Co}$ sources was used BEBIG ${ }^{\mathrm{TM}}$ model of cobalt- 60 source was simulated by using Fluka [6] as a Monte Carlo method and TG-43U1 dosimetric parameters such as radial-dose function, doserate constant, $2 \mathrm{D}$ anisotropy function and the air-Kerma strength were computed. Lastly, the achieved results by the Fluka code were compared with the obtained results using a similar model source which was GEANT and MCNP codes.

\section{Materials and Methods}

\section{${ }^{60}$ Co seed description}

Structure of brachytherapy source of new BEBIGTM ${ }^{60} \mathrm{Co}$ [7] differs slightly from the old type [8]. The usage of ${ }^{60} \mathrm{Co}$ in brachytherapy is in the form of cylindrical seeds with a length of $3.5 \mathrm{~mm}$ and a diameter of $0.5 \mathrm{~mm}$. Details are shown in (Figure 1).

A seed of ${ }^{60} \mathrm{Co}$ with the mentioned dimensions in (Figure 1) is simulated by considering the center of active area coincide with the center of coordinate system. Also the energies that were considered for the definition of the source are two gamma rays of ${ }^{60} \mathrm{Co}$ with energies of $1.33 \mathrm{MeV}$ and $1.17 \mathrm{MeV}$. However, the other sources of energy have been neglected due to their insignificant amount. In addition, cut off energy of the passing photon in all calculations is considered as $10 \mathrm{keV}$.

\section{Fluka Monte Carlo code}

In this study, in order to simulate the $\mathrm{BEBIG}^{\mathrm{TM}}{ }^{60} \mathrm{Co}$ brachytherapy source, the Monte Carlo Fluka version 2013.5.10 ("Flair" version 1.1-3 [R2519]) was used. The Fluka method is one of the simulating programs for physical particles, which uses Monte Carlo method. The

*Corresponding author: Mahdi Sadeghi, Department of Medical physics, Schoo of Medicine, Iran University of Medical Science, Tehran, Iran, E-mail: sadeghi.m@ iums.ac.ir

Received June 30, 2018; Accepted July 10, 2018; Published July18, 2018

Citation: Sadeghi M, Davoudi A, allaf MA, Jafari A (2018) Investigation of Dosimetric Parameters of HDR Cobalt-60 after-loading Brachytherapy Source using Monte Carlo Fluka Code. J Nucl Med Radiat Ther 9: 366. doi: 10.4172/21559619.1000366

Copyright: @ 2018 Sadeghi M, et al. This is an open-access article distributed under the terms of the Creative Commons Attribution License, which permits unrestricted use, distribution, and reproduction in any medium, provided the original author and source are credited. 


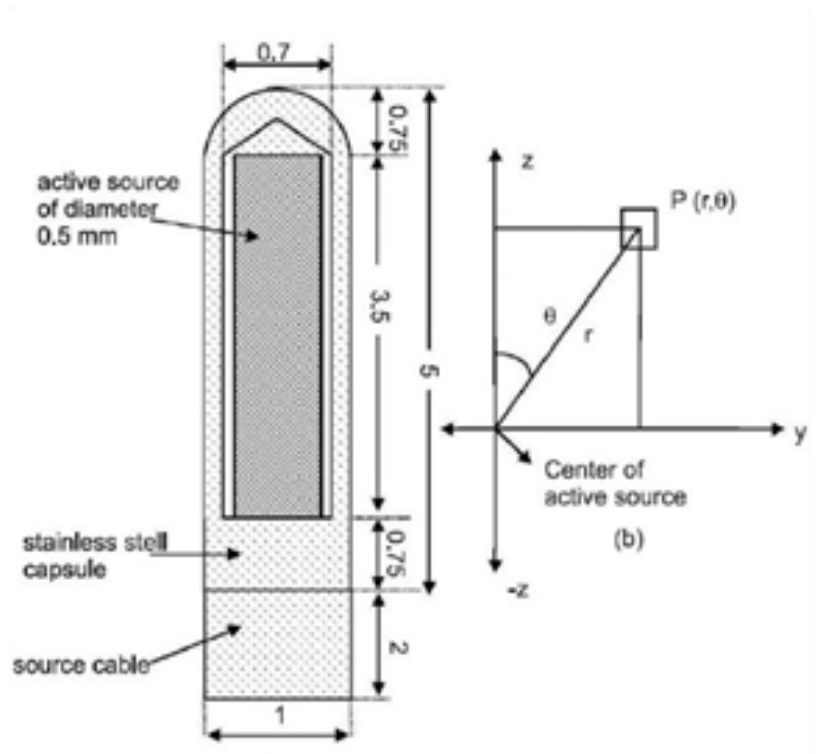

(a)

Figure 1: (a) Schematic diagram of the new BEBIG ${ }^{T M}{ }^{60} \mathrm{Co} H D R$ source in the Monte Carlo simulations. Dimensions are shown in millimeters (not to scale) (b) The co-ordinate system used in the Monte Carlo simulations [9].

main advantage of this method is high accuracy in a wide range of energy in simulation.For instance, this code can calculate interaction and diffusion processes of 60 different particles [6]. These particles include photons and electrons with $1 \mathrm{keV}$ to thousands of $\mathrm{TeV}$, neutron with any energy level, hadrons of energies up to $20 \mathrm{TeV}$. In addition, by linking the Fluka code with DPMJET code, calculation and simulation of energies up to $10 \mathrm{PeV}$ and all antiparticles and massive particles could be possible [10]. A personal computer with specification: CPU: Intel'Celeron $4301.8 \mathrm{GHz}$ was used for all calculation processes.

BEBIG ${ }^{\mathrm{TM}}$ Cobalt- 60 was modeled with a dosimetric characterization including material, atomic composition and their density were taken from (Table 1) [11]. Consequently, the simulated source was placed in center of four different cylindrical phantoms with the same diameter and length as long as $100 \mathrm{~cm}$.

Different phantoms based on their major materials including water, PMMA, Polystyrene and RW1 were designed. Figure 2 shows the seed of ${ }^{60} \mathrm{Co}$ brachytherapy in water phantom that is simulated by Fluka code. The amounts of the absorbed radiation from different distance to each phantom were calculated $(\mathrm{GeV} / \mathrm{g})$. The data related to the constituent elements of each phantom are presented on (Table 2).

To obtain suitable dose from the source, a detector simulator in different parts is needed. In this research, for a definition of the detector applying Fluka code, the presented method by Anjomrouz et al. [10] and Hadadi et al. has been employed [13]. This method utilizes virtual cylinders that classified in USRBIN card and lattice structure of R- $\phi-Z$. The network detectors are designed at a distance of $10 \mathrm{~cm}$ from the center of coordinate system in the form of cylindrical shells with different dimensions (Figure 3). The lattice system for detectors was used due to the ease of finding dosage in any desired point in 3 dimensions with distance up to $10 \mathrm{~cm}$ from the center, the reduced process time, and the increased accuracy.

AAPM and working group of High Energy Brachytherapy Dosimetry (HEBD) presented a comprehensive report, which had

\begin{tabular}{|c|c|c|c|}
\hline Component & $\begin{array}{c}\text { Source } \\
\text { material }\end{array}$ & Atomic composition (\%) & $\begin{array}{c}\text { Density } \\
\mathbf{c m}^{3} \mathbf{( g /}\end{array}$ \\
\hline Active source & Cobalt & 100 & 8.9 \\
\hline Encapsulation & $\begin{array}{c}\text { Stainless steel } \\
\text { (AISI 316L) }\end{array}$ & $\begin{array}{c}\mathrm{C}(0.026), \mathrm{Mn}(1.4), \mathrm{Si}(0.42), \\
\mathrm{P}(0.019), \mathrm{S}(0.003), \mathrm{Cr} \\
(16.8), \mathrm{Mo}(2.11), \mathrm{Ni}(11.01), \\
\mathrm{Fe}(68.21)\end{array}$ & 7.8 \\
\hline
\end{tabular}

Table 1: Atomic composition by weight and density of the new BEBIG ${ }^{\mathrm{TM}}{ }^{60} \mathrm{Co}$ HDR source [12]

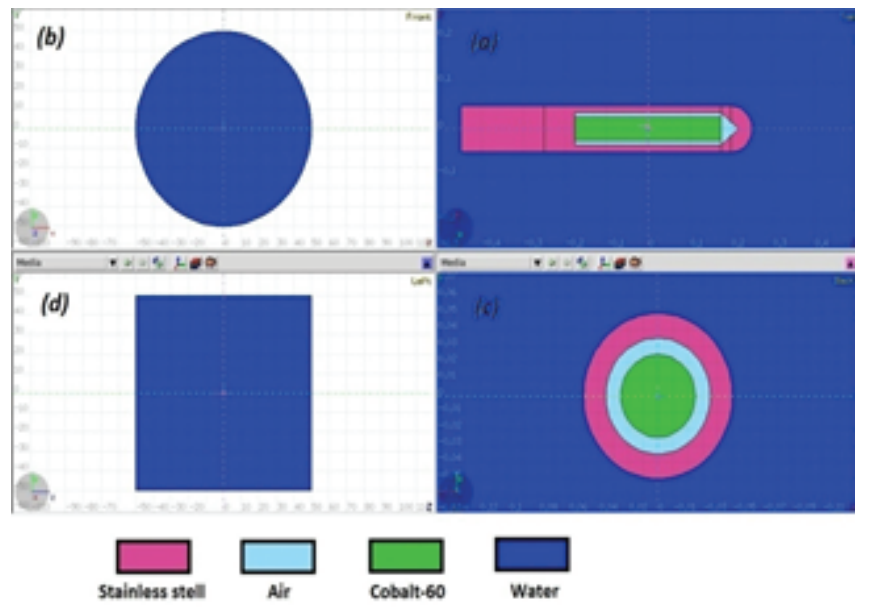

Figure 2: (a) Cutaway view in $Z$ direction shows a seed of ${ }^{60} \mathrm{Co}$ brachytherapy in water phantom. (b) view of base of cylindrical water phantom. (c) cutaway view perpendicular to $Z$ direction shows seed of ${ }^{60} \mathrm{Co}$ brachytherapy in water phantom. (d) cutaway view in $Z$ direction (height) of cylindrical water phantom

concentrated on dosage calculation of brachytherapy sources with average photon energy level higher than $50 \mathrm{KeV}$ [13]. According to both standard ways of cylindrical source classifications, $2 \mathrm{D}$ dosage rate formula is demonstrated in formula-1 [13].

$$
\dot{D}(r, \theta)=S_{k} \Lambda \frac{G(r, \theta)}{G\left(r_{0}, \theta_{0}\right)} g(r) F(r, \theta)
$$

For calculation of Kerma, seed of ${ }^{60} \mathrm{Co}$ brachytherapy was located in center of a vacuumed phantom and by using an air-assisted detector which inserted among the internal space between two spherical skins with radiuses of 97.5 and $102.5 \mathrm{~cm}$ and a cone with angular aperture of 4 , absorbed energy is calculated (Figure 4) [12].

By running the Fluka program the absorbed energy that is acquired per $\mathrm{GeV}$ is $\mathrm{E}=1.0434 \mathrm{GeV}$ and by applying Kerma calculation formula and necessary unit conversion the value of $8.1747 \times 10^{-7} \mathrm{~Gy}$ is obtained. Air-Kerma Strength in distance of "d" from center of a source is calculated from below formula

$$
S_{K}=\dot{K}(d) \cdot d^{2}
$$

Using output of the program and parameters in formula no. 2 value for $\mathrm{S}_{\mathrm{k}} / \mathrm{A}$ is calculated as $2.9429 \times 10^{-7}\left(\mathrm{cGy} \cdot \mathrm{cm}^{2} / \mathrm{h} \cdot \mathrm{Bq}\right)$. Doserate constant is defined in lateral direction with distance of $1 \mathrm{~cm}$ from geometrical center of a source with strength of 1 air-Kerma and is calculated from following formula.

$$
\wedge=\dot{D} \frac{\left(r_{0}, \theta_{0}\right)}{S_{k}}
$$

Using (formula 3) and make necessary unit conversion, value of 
Citation: Sadeghi M, Davoudi A, allaf MA, Jafari A (2018) Investigation of Dosimetric Parameters of HDR Cobalt-60 after-loading Brachytherapy Source using Monte Carlo Fluka Code. J Nucl Med Radiat Ther 9: 366. doi: 10.4172/2155-9619.1000366

Page 3 of 7

\begin{tabular}{|c|c|c|c|c|c|c|c|}
\hline Element & \multicolumn{2}{|c|}{$\mathbf{Z}$} & \multirow{2}{*}{$\begin{array}{c}\text { A } \\
1.008\end{array}$} & \multirow{2}{*}{$\begin{array}{l}\text { water } \\
0.112\end{array}$} & \multirow{2}{*}{$\begin{array}{l}\text { RW1 } \\
0.132\end{array}$} & \multirow{2}{*}{$\begin{array}{l}\text { PMMA } \\
0.081\end{array}$} & \multirow{2}{*}{$\begin{array}{c}\text { Polystyrene } \\
0.077\end{array}$} \\
\hline \multirow{7}{*}{ Composition and mass fraction in $\%$} & $\mathrm{H}$ & 1 & & & & & \\
\hline & C & 6 & 12.011 & - & 0.794 & 0.6 & 0.923 \\
\hline & $\mathrm{N}$ & 7 & 14.007 & - & - & - & - \\
\hline & $\mathrm{O}$ & 8 & 15.999 & 0.888 & 0.038 & 0.32 & - \\
\hline & $\mathrm{Mg}$ & 12 & 24.305 & - & 0.009 & - & - \\
\hline & $\mathrm{Cl}$ & 17 & 35.457 & - & 0.027 & - & - \\
\hline & $\mathrm{Ca}$ & 20 & 40.078 & - & - & - & - \\
\hline Mass density $\left(\mathrm{g} / \mathrm{cm}^{3}\right)$ & - & - & - & 0.998 & 0.97 & 1.19 & 1.06 \\
\hline Zeff.(calculated) & - & - & - & 7.416 & 7.21 & 6.096 & 5.584 \\
\hline
\end{tabular}

Table 2: Elemental composition, mass fraction, density and $Z_{\text {eff }}$ of water and water-substitute solid phantom materials [12].
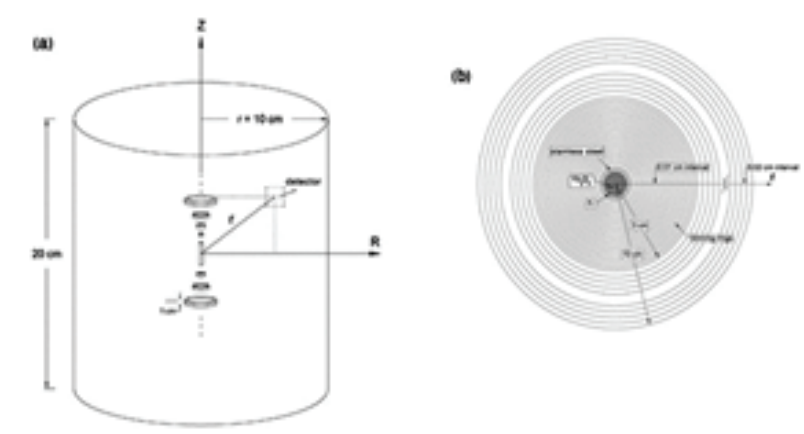

Figure 3: Configuration of region inning by FLUKA for geometry of detectors: (a) The view of virtual cylindrical rings; (b) cross-sectional view of sources along with ring detectors [13]

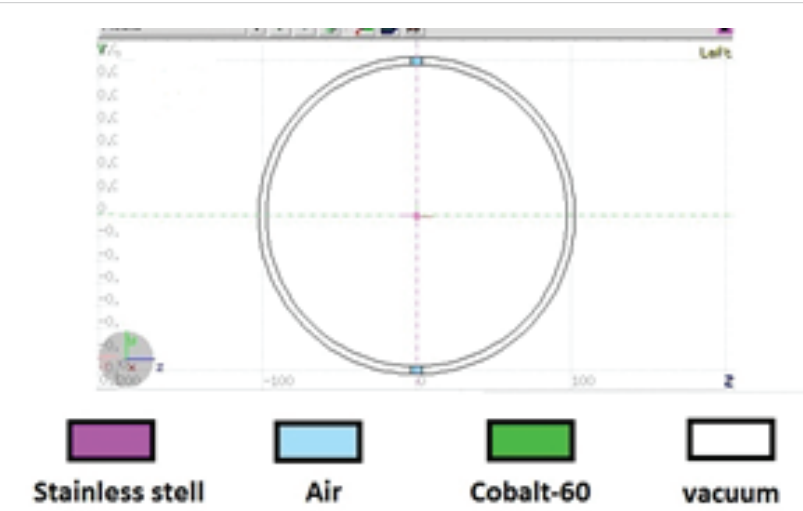

Figure 4: Cut away view in $Z$ direction shows position of air-assisted detector relative to the seed of ${ }^{60} \mathrm{Co}$ brachytherapy inside of an internal sphere of the vacuum phantom.

dose-rate constant for different phantoms achieved as following values: $\Lambda_{\text {water }}=1.0936(\mathrm{cGy} / \mathrm{h} \mathrm{U}), \Lambda_{\text {PMMA }}=1.0662(\mathrm{cGy} / \mathrm{h} \mathrm{U}), \Lambda_{\text {poly }}=1.072$ (cGy/h U), $\Lambda_{\mathrm{RW1}}=1.0662$ (cGy/h U).

\section{Results}

The value of radial dose function of four different phantoms has been presented on (Table 3). Also, the radial dose function based on different distances is shown in (Figure 5).

Eventually the estimated dosimetric parameters are demonstrated

\begin{tabular}{|c|c|c|c|c|}
\hline $\mathbf{r}$ & $\mathbf{g}(\mathbf{r})$-water & $\mathbf{g}(\mathbf{r})$-PMMA & $\mathbf{g}(\mathbf{r})$-polystyrene & $\mathbf{g}(\mathbf{r})$-RW1 \\
\hline 0.5 & 0.968 & 0.94 & 0.943 & 0.968 \\
\hline 1 & 1 & 1 & 1 & 1 \\
\hline 2 & 1.012 & 0.999 & 0.962 & 0.972 \\
\hline 3 & 0.997 & 0.972 & 0.992 & 0.972 \\
\hline 4 & 0.925 & 0.945 & 0.939 & 0.956 \\
\hline 5 & 0.971 & 0.943 & 0.924 & 0.947 \\
\hline 6 & 0.938 & 0.926 & 0.928 & 0.942 \\
\hline 7 & 0.939 & 0.882 & 0.898 & 0.913 \\
\hline 8 & 0.901 & 0.823 & 0.9 & 0.91 \\
\hline 9 & 0.863 & 0.9 & 0.886 & 0.846 \\
\hline 10 & 0.892 & 0.847 & 0.849 & 0.86 \\
\hline
\end{tabular}

Table 3: Radial dose function calculated in water phantom for BEBIGTM ${ }^{60} \mathrm{Co}$ HDR source.

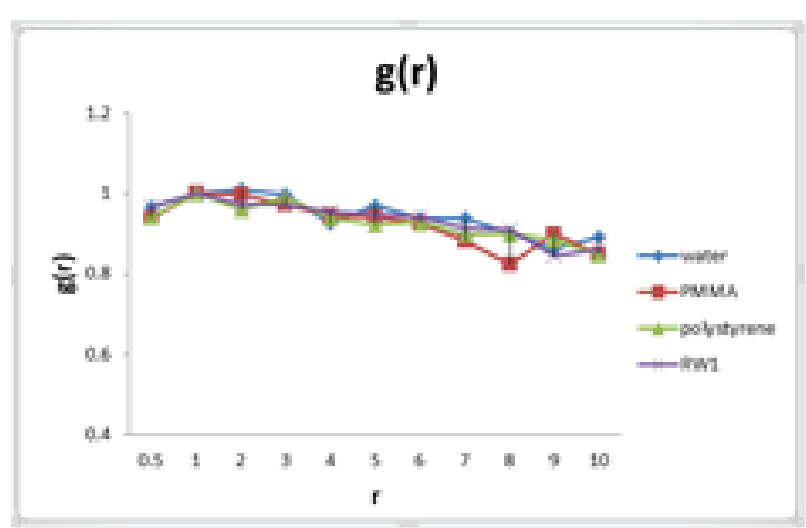

Figure 5: Comparison of $\mathrm{g}(\mathrm{r})$ obtained in four different phantoms.

on (Tables 4-7). These data shows that, considering a constant distance and by increasing the angles, the dose rate in the phantom is increased. Conversely, in a constant angel, increasing distance leading to lower dose rates. In this calculation using Fluka simulation, the value of air Kerma Strength per activity was $2.9429 \times 10^{-7} \mathrm{cGy} \cdot \mathrm{cm}^{2} / \mathrm{h} \cdot \mathrm{Bq}$. Also, the value of dose-rate constant for water phantom was estimated 1.0936 $\mathrm{cGy} / \mathrm{h} \cdot \mathrm{U}$.

\section{Discussion}


Citation: Sadeghi M, Davoudi A, allaf MA, Jafari A (2018) Investigation of Dosimetric Parameters of HDR Cobalt-60 after-loading Brachytherapy Source using Monte Carlo Fluka Code. J Nucl Med Radiat Ther 9: 366. doi: 10.4172/2155-9619.1000366

Page 4 of 7

\begin{tabular}{|c|c|c|c|c|c|c|c|c|c|c|c|}
\hline \multirow{2}{*}{$\theta$ (deg) } & \multicolumn{11}{|c|}{$r(\mathrm{~cm})$} \\
\hline & 0.5 & 1 & 2 & 3 & 4 & 5 & 6 & 7 & 8 & 9 & 10 \\
\hline 0 & $6.57 \mathrm{E}-07$ & $2.78 \mathrm{E}-07$ & $6.97 \mathrm{E}-08$ & 2.84E-08 & 1.76E-08 & 8.91E-09 & 8.48E-09 & 4.00E-09 & 3.95E-09 & 3.16E-09 & 2.40E-09 \\
\hline 10 & 7.38E-07 & 2.31E-07 & $6.64 \mathrm{E}-08$ & $3.11 \mathrm{E}-08$ & $1.80 \mathrm{E}-08$ & $1.26 \mathrm{E}-08$ & $6.51 \mathrm{E}-09$ & $5.10 \mathrm{E}-09$ & 4.51E-09 & 3.44E-09 & 2.90E-09 \\
\hline 20 & $7.78 \mathrm{E}-07$ & $2.51 \mathrm{E}-07$ & $6.88 \mathrm{E}-08$ & $3.21 \mathrm{E}-08$ & $1.80 \mathrm{E}-08$ & $1.04 \mathrm{E}-08$ & 8.35E-09 & 4.91E-09 & 4.36E-09 & 3.22E-09 & 2.60E-09 \\
\hline 30 & $8.25 \mathrm{E}-07$ & $2.59 \mathrm{E}-07$ & $6.99 \mathrm{E}-08$ & 3.22E-08 & 1.76E-08 & $1.08 \mathrm{E}-08$ & 8.35E-09 & $6.29 \mathrm{E}-09$ & 4.37E-09 & 3.59E-09 & $2.70 \mathrm{E}-09$ \\
\hline 40 & $8.59 \mathrm{E}-07$ & 2.57E-07 & $7.22 \mathrm{E}-08$ & $3.21 \mathrm{E}-08$ & 1.84E-08 & 1.19E-08 & $8.12 \mathrm{E}-09$ & $5.65 \mathrm{E}-09$ & 4.45E-09 & 3.42E-09 & 2.90E-09 \\
\hline 50 & 8.99E-07 & $2.72 \mathrm{E}-07$ & 7.16E-08 & 3.34E-08 & 1.87E-08 & $1.18 \mathrm{E}-08$ & 8.35E-09 & $5.50 \mathrm{E}-09$ & $4.68 \mathrm{E}-09$ & 3.71E-09 & 2.90E-09 \\
\hline 60 & $9.51 \mathrm{E}-07$ & 2.77E-07 & $7.28 \mathrm{E}-08$ & 3.29E-08 & 1.99E-08 & $1.22 \mathrm{E}-08$ & 7.78E-09 & $5.88 \mathrm{E}-09$ & $4.29 \mathrm{E}-09$ & 3.37E-09 & 2.60E-09 \\
\hline 70 & $1.00 \mathrm{E}-06$ & 2.92E-07 & 7.97E-08 & 3.50E-08 & 1.87E-08 & 1.23E-08 & 8.47E-09 & $6.11 \mathrm{E}-09$ & 4.70E-09 & 3.38E-09 & 2.90E-09 \\
\hline 80 & 1.11E-06 & 3.07E-07 & 7.74E-08 & 3.38E-08 & 1.91E-08 & 1.25E-08 & 8.47E-09 & 6.23E-09 & 4.63E-09 & 3.60E-09 & 2.80E-09 \\
\hline 90 & $1.21 \mathrm{E}-06$ & 3.22E-07 & $8.20 \mathrm{E}-08$ & 3.60E-08 & $1.88 \mathrm{E}-08$ & $1.26 \mathrm{E}-08$ & 8.47E-09 & $6.23 \mathrm{E}-09$ & $4.58 \mathrm{E}-09$ & 3.46E-09 & 2.90E-09 \\
\hline
\end{tabular}

Table 4: Dose rate in water phantom for the new BEBIG ${ }^{\mathrm{TM}}{ }^{60} \mathrm{Co}$ source based $\left(\mathrm{cGy}^{2} \cdot \mathrm{cm}^{2} / \mathrm{h}^{2} \cdot \mathrm{Bq} \cdot \mathrm{U}\right)$.

\begin{tabular}{|c|c|c|c|c|c|c|c|c|c|c|c|}
\hline \multirow{2}{*}{$\theta$ (deg) } & \multicolumn{11}{|c|}{$r(\mathrm{~cm})$} \\
\hline & 0.5 & 1 & 2 & 3 & 4 & 5 & 6 & 7 & 8 & 9 & 10 \\
\hline 0 & $6.57 \mathrm{E}-07$ & $2.38 \mathrm{E}-06$ & $3.70 \mathrm{E}-08$ & 1.96E-08 & $1.59 \mathrm{E}-08$ & $9.50 \mathrm{E}-09$ & $5.18 \mathrm{E}-09$ & 4.43E-09 & 3.32E-09 & 3.09E-09 & $2.20 \mathrm{E}-09$ \\
\hline 10 & 7.38E-07 & 2.39E-06 & $6.53 \mathrm{E}-08$ & 2.93E-08 & $1.68 \mathrm{E}-08$ & $9.02 \mathrm{E}-09$ & 7.65E-09 & 4.97E-09 & 3.89E-09 & 3.30E-09 & 2.70E-09 \\
\hline 20 & $7.65 \mathrm{E}-07$ & $2.34 \mathrm{E}-06$ & $6.60 \mathrm{E}-08$ & $2.98 \mathrm{E}-08$ & 1.76E-08 & 1.10E-08 & 7.41E-09 & $6.03 \mathrm{E}-09$ & 4.43E-09 & $3.41 \mathrm{E}-09$ & $2.80 \mathrm{E}-09$ \\
\hline 30 & 7.93E-07 & $2.55 \mathrm{E}-06$ & $6.76 \mathrm{E}-08$ & 3.09E-08 & 1.77E-08 & 1.11E-08 & 7.43E-09 & $5.40 \mathrm{E}-09$ & 4.09E-09 & 3.24E-09 & $2.20 \mathrm{E}-09$ \\
\hline 40 & 8.42E-07 & $2.50 \mathrm{E}-06$ & 7.06E-08 & 3.19E-08 & $1.74 \mathrm{E}-08$ & 1.09E-08 & 7.92E-09 & 5.91E-09 & 4.55E-09 & 3.43E-09 & 2.60E-09 \\
\hline 50 & $8.64 \mathrm{E}-07$ & $2.57 \mathrm{E}-06$ & $6.98 \mathrm{E}-08$ & $3.20 \mathrm{E}-08$ & 1.80E-08 & 1.17E-08 & 7.54E-09 & 5.56E-09 & $4.38 \mathrm{E}-09$ & 3.24E-09 & $2.50 \mathrm{E}-09$ \\
\hline 60 & $9.23 \mathrm{E}-07$ & $2.69 \mathrm{E}-06$ & 7.26E-08 & $3.19 \mathrm{E}-08$ & $1.82 \mathrm{E}-08$ & $1.11 \mathrm{E}-08$ & $8.16 \mathrm{E}-09$ & $5.63 \mathrm{E}-09$ & $4.54 \mathrm{E}-09$ & $3.20 \mathrm{E}-09$ & $2.60 \mathrm{E}-09$ \\
\hline 70 & $9.68 \mathrm{E}-07$ & 2.82E-06 & 7.45E-08 & 3.34E-08 & $1.86 \mathrm{E}-08$ & 1.15E-08 & $8.08 \mathrm{E}-09$ & $5.66 \mathrm{E}-09$ & 4.46E-09 & 2.95E-09 & $2.80 \mathrm{E}-09$ \\
\hline 80 & 1.05E-06 & 2.96E-06 & 8.02E-08 & $3.53 \mathrm{E}-08$ & 1.93E-08 & 1.19E-08 & 8.01E-09 & 5.49E-09 & 4.03E-09 & 3.20E-09 & $2.50 \mathrm{E}-09$ \\
\hline 90 & 1.15E-06 & $3.14 \mathrm{E}-07$ & 7.90E-08 & $3.42 \mathrm{E}-08$ & $1.87 \mathrm{E}-08$ & $1.20 \mathrm{E}-08$ & $8.15 \mathrm{E}-09$ & $5.70 \mathrm{E}-09$ & $4.08 \mathrm{E}-09$ & $3.52 \mathrm{E}-09$ & $2.70 \mathrm{E}-09$ \\
\hline
\end{tabular}

Table 5: Dose rate in PMMA phantom for the new BEBIGTM ${ }^{60} \mathrm{Co}$ source based $\left(\mathrm{cGy}^{2} \cdot \mathrm{cm}^{2} / \mathrm{h}^{2} \cdot \mathrm{Bq} \cdot \mathrm{U}\right)$.

\begin{tabular}{|c|c|c|c|c|c|c|c|c|c|c|c|}
\hline \multirow[t]{2}{*}{$\theta$ (deg) } & \multicolumn{11}{|c|}{$r(\mathrm{~cm})$} \\
\hline & 0.5 & 1 & 2 & 3 & 4 & 5 & 6 & 7 & 8 & 9 & 10 \\
\hline 0 & 8.29E-07 & $2.55 \mathrm{E}-07$ & $6.86 \mathrm{E}-08$ & $2.40 \mathrm{E}-08$ & $1.46 \mathrm{E}-08$ & 9.69E-09 & 7.53E-09 & 4.49E-09 & 4.26E-09 & 3.01E-09 & 2.40E-09 \\
\hline 10 & $7.26 \mathrm{E}-07$ & 2.17E-07 & $6.52 \mathrm{E}-08$ & 2.93E-08 & 1.66E-08 & 1.09E-08 & 7.81E-09 & 5.03E-09 & 4.07E-09 & 3.00E-09 & $2.80 \mathrm{E}-09$ \\
\hline 20 & 7.53E-07 & 2.33E-07 & $6.80 \mathrm{E}-08$ & 2.93E-08 & 1.79E-08 & 1.06E-08 & 7.26E-09 & 4.69E-09 & 4.56E-09 & 3.52E-09 & 2.40E-09 \\
\hline 30 & 7.75E-07 & $2.58 \mathrm{E}-07$ & 7.00E-08 & $3.24 \mathrm{E}-08$ & $1.82 \mathrm{E}-08$ & 2.30E-08 & 7.78E-09 & 5.48E-09 & 4.39E-09 & 3.11E-09 & $2.40 \mathrm{E}-09$ \\
\hline 40 & 8.33E-07 & $2.54 \mathrm{E}-07$ & $6.90 \mathrm{E}-08$ & $3.15 \mathrm{E}-08$ & $1.82 \mathrm{E}-08$ & 1.16E-08 & 7.49E-09 & 5.93E-09 & 4.09E-09 & 3.46E-09 & $2.70 \mathrm{E}-09$ \\
\hline 50 & 8.71E-07 & 2.65E-07 & 7.15E-08 & 3.31E-08 & $1.73 \mathrm{E}-08$ & 1.16E-08 & 7.66E-09 & 5.76E-09 & 4.51E-09 & 3.22E-09 & 2.40E-09 \\
\hline 60 & $9.20 \mathrm{E}-07$ & $2.70 \mathrm{E}-07$ & 7.41E-08 & $3.16 \mathrm{E}-08$ & 1.83E-08 & 1.15E-08 & 8.11E-09 & $5.60 \mathrm{E}-09$ & 4.25E-09 & 3.40E-09 & $2.90 \mathrm{E}-09$ \\
\hline 70 & $9.71 \mathrm{E}-07$ & $2.83 \mathrm{E}-08$ & 7.64E-08 & 3.32E-08 & $1.95 \mathrm{E}-08$ & 1.16E-08 & 7.91E-09 & 5.64E-09 & 4.41E-09 & 3.44E-09 & $2.70 \mathrm{E}-09$ \\
\hline 80 & $1.05 \mathrm{E}-06$ & $2.98 \mathrm{E}-07$ & 7.55E-08 & 3.38E-08 & $1.88 \mathrm{E}-08$ & $1.18 \mathrm{E}-08$ & 8.35E-09 & 6.03E-09 & 4.59E-09 & 3.33E-09 & $2.70 \mathrm{E}-09$ \\
\hline 90 & 1.16E-06 & 3.15E-07 & 7.65E-08 & 3.51E-08 & $1.87 \mathrm{E}-08$ & 1.18E-08 & 8.21E-09 & 5.84E-09 & 4.48E-09 & 3.49E-09 & 2.70E-09 \\
\hline
\end{tabular}

Table 6: Dose rate in Polystyrene phantom for the new BEBIGTM ${ }^{60} \mathrm{Co}$ source based $\left(\mathrm{cGy}^{2} \cdot \mathrm{cm}^{2} / \mathrm{h}^{2} \cdot \mathrm{Bq} \cdot \mathrm{U}\right)$.

As seen in (Figures 6-9), the obtained values of radial dose function of four different phantoms in this study were compared to the achieved data using MCNP code.

The air Kerma Strength per activity value using Fluka has been estimated $2.9429 \times 10^{-7} \mathrm{cGy} \cdot \mathrm{cm}^{2} / \mathrm{h} \cdot \mathrm{Bq}$ and the value estimated by MCNP code [13] was $3.04 \times 10^{-7} \pm 0.05 \% \mathrm{cGy} \cdot \mathrm{cm}^{2} / \mathrm{h} \cdot \mathrm{Bq}$. It can be seen that the air-Kerma strength in Fluka differs a bit from the MCNP code because of the differences in the programming language of each code, possible differences in the geometry definition for brachytherapy seeds and detectors, as well as differences in the method of calculating the
Kerma strength either from calculations or simulations method. Also, the dose-rate constant value for water phantom was estimated 1.0936 cGy/h.U. Using MCNP code [9] the value was reported $1.086 \pm 0.06 \%$ $\mathrm{cGy} / \mathrm{h} \cdot \mathrm{U}$ and using GEANT code [9] the value was reported $1.017 \pm$ $0.011 \% \mathrm{cGy} / \mathrm{h} \cdot \mathrm{U}$

Considering the presented values come from Fluka simulation and comparison with the results of MCNP and GEANT codes, it can be concluded that the new BEBIG ${ }^{\mathrm{TM}}{ }^{60} \mathrm{Co}$ source can be a good replacement for 192 Irin after loading brachytherapy since it has higher half time which results in more economical application. 
Citation: Sadeghi M, Davoudi A, allaf MA, Jafari A (2018) Investigation of Dosimetric Parameters of HDR Cobalt-60 after-loading Brachytherapy Source using Monte Carlo Fluka Code. J Nucl Med Radiat Ther 9: 366. doi: 10.4172/2155-9619.1000366

Page 5 of 7

\begin{tabular}{|c|c|c|c|c|c|c|c|c|c|c|c|}
\hline \multirow{2}{*}{$\Theta(\mathrm{deg})$} & \multicolumn{11}{|c|}{$r(\mathrm{~cm})$} \\
\hline & 0.5 & 1 & 2 & 3 & 4 & 5 & 6 & 7 & 8 & 9 & 10 \\
\hline 0 & 8.46E-07 & 2.33E-07 & $6.46 \mathrm{E}-08$ & 2.33E-08 & $1.54 \mathrm{E}-08$ & 9.76E-09 & 7.40E-09 & 4.54E-09 & 4.07E-09 & 3.01E-09 & $2.40 \mathrm{E}-09$ \\
\hline 10 & 7.36E-07 & 2.30E-07 & $6.11 \mathrm{E}-08$ & 2.93E-08 & 1.66E-08 & $1.08 \mathrm{E}-08$ & 7.50E-09 & 4.70E-09 & 4.10E-09 & 3.01E-09 & 2.40E-09 \\
\hline 20 & 7.63E-07 & 2.47E-07 & 6.46E-08 & 2.94E-08 & $1.79 \mathrm{E}-08$ & 1.06E-08 & 7.54E-09 & 5.04E-09 & 4.16E-09 & 3.04E-09 & 2.40E-09 \\
\hline 30 & 7.84E-07 & $2.54 \mathrm{E}-07$ & 6.66E-08 & $3.12 \mathrm{E}-08$ & 1.82E-08 & $1.08 \mathrm{E}-08$ & 7.56E-09 & 5.54E-09 & 4.17E-09 & 3.07E-09 & $2.50 \mathrm{E}-09$ \\
\hline 40 & 8.38E-07 & $2.58 \mathrm{E}-07$ & 6.82E-08 & 3.23E-08 & 1.82E-08 & 1.09E-08 & 7.58E-09 & 5.61E-09 & 4.20E-09 & 3.13E-09 & $2.50 \mathrm{E}-09$ \\
\hline 50 & 8.76E-07 & 2.69E-07 & 7.08E-08 & 3.27E-08 & $1.82 \mathrm{E}-08$ & 1.13E-08 & 7.67E-09 & 5.65E-09 & 4.25E-09 & 3.19E-09 & 2.60E-09 \\
\hline 60 & $9.25 \mathrm{E}-07$ & 2.74E-07 & 7.34E-08 & 3.31E-08 & $1.83 \mathrm{E}-08$ & 1.15E-08 & 7.93E-09 & 5.68E-09 & 4.26E-09 & 3.23E-09 & $3.20 \mathrm{E}-09$ \\
\hline 70 & 9.79E-07 & 2.88E-07 & 7.57E-08 & 3.32E-08 & 1.85E-08 & 1.17E-08 & 8.13E-09 & 5.76E-09 & 4.30E-09 & 3.24E-09 & 2.60E-09 \\
\hline 80 & $1.06 \mathrm{E}-06$ & 3.02E-07 & 7.66E-08 & 3.38E-08 & 1.87E-08 & 1.19E-08 & 8.20E-09 & 5.78E-09 & 4.42E-09 & 3.25E-09 & 2.70E-09 \\
\hline 90 & 1.18E-06 & 3.14E-07 & 7.68E-08 & 3.42E-08 & 1.89E-08 & 1.20E-08 & 8.29E-09 & 5.90E-09 & 4.51E-09 & 3.31E-09 & 2.70E-09 \\
\hline
\end{tabular}

Table 7: Dose rate in RW1 phantom for the new BEBIG ${ }^{\mathrm{TM}}{ }^{60} \mathrm{Co}$ source based $\left(\mathrm{cGy}^{2} \cdot \mathrm{cm}^{2} / \mathrm{h}^{2} \cdot \mathrm{Bq} \cdot \mathrm{U}\right)$.

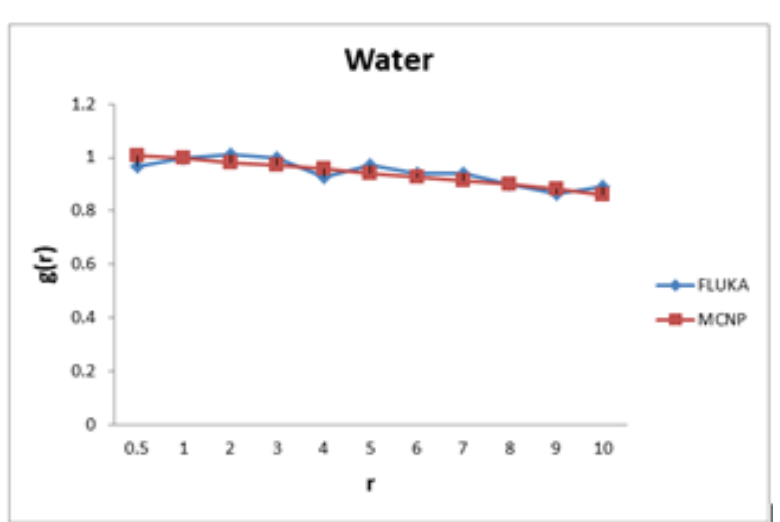

Figure 6: Comparison of $\mathrm{g}(\mathrm{r})$ for the new $\mathrm{BEBIG}{ }^{\mathrm{TM}}{ }^{60} \mathrm{Co}$ source in water phantom using MCNP code [12] and Fluka code.

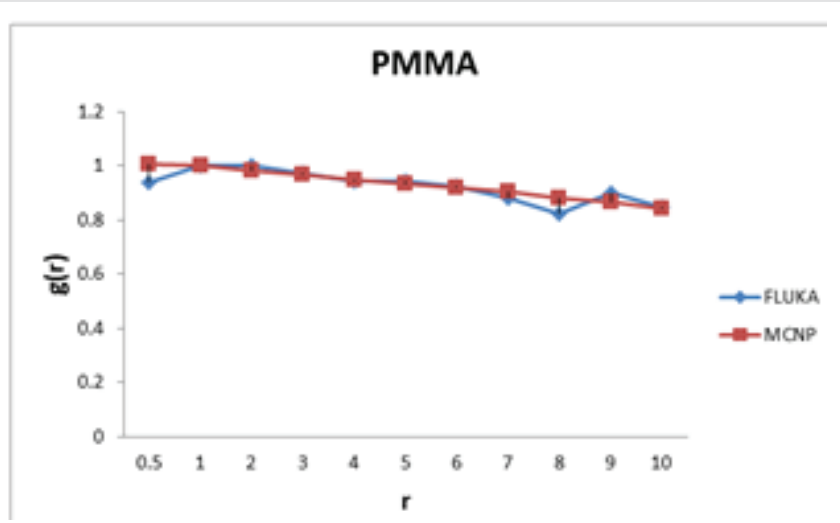

Figure 7: Comparison of $g(r)$ for the new BEBIG ${ }^{T M}{ }^{60}$ Co source in PMMA phantom using MCNP code [12] and Fluka code.

\section{Acknowledgments}

The authors would like to thank Ms. Narges Ahadian for her assistance in editing this paper.

\section{References}

1. Strohmaier S, Zwierzchowski G (2011) Comparison of ${ }^{60} \mathrm{Co}$ and ${ }^{192} \mathrm{Ir}$ sources in HDR brachytherapy. J Contemp Brachyther 3: 199-208.

2. Eksir Monfared M, Najm Abadi F (2008) The Physics of Radiotherapy.

3. Update of Report of American Association of Physicists in Medicine (AAPM) Radiation Therapy Committee. No. 43 Report 2004.Granero D, PérezCalatayud J, Ballester F (2007) Technical note: Dosimetric study of a new Co-

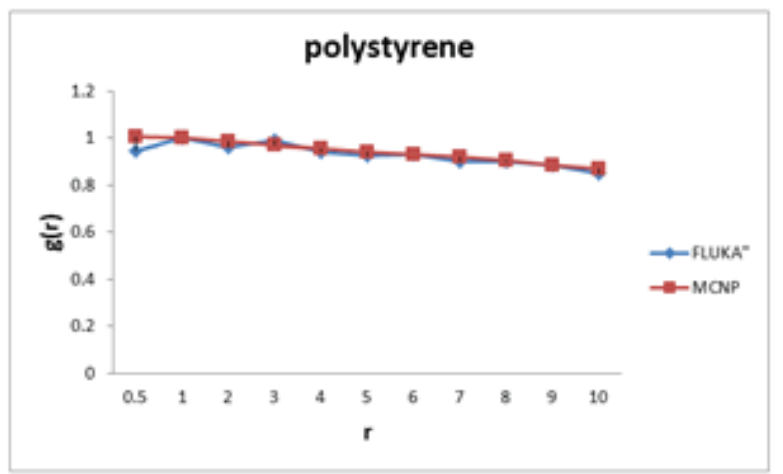

Figure 8: Comparison of $g(r)$ for the new BEBIG ${ }^{\mathrm{TM}}{ }^{60} \mathrm{Co}$ source in Polystyrene phantom using MCNP code [12] and Fluka code.

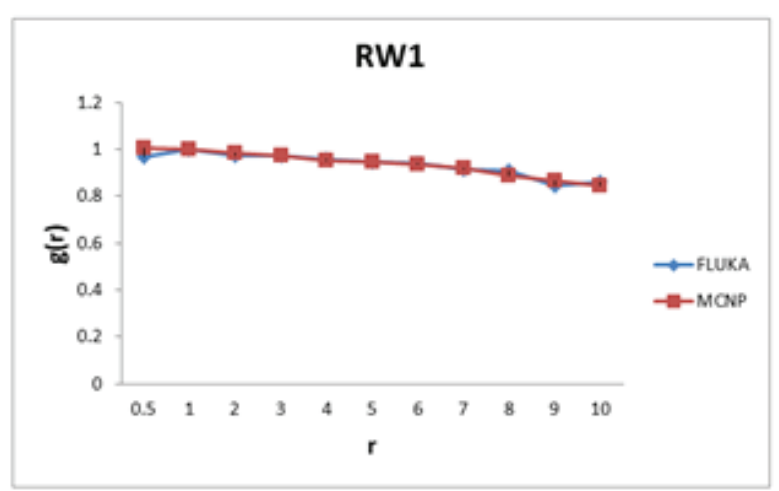

Figure 9: Comparison of $\mathrm{g}(\mathrm{r})$ for the new BEBIG ${ }^{\mathrm{TM}}{ }^{60} \mathrm{Co}$ source in RW1 phantom using MCNP code [12] and Fluka code.

60 source used in brachytherapy. Med Phys 34: 3485-3488.

4. Ballester F, Granero D, Pérez-Calatayud J, Casal E, Agramunt S (2005) Monte Carlo dosimetric study of the BEBIG Co-60 HDR source. Phys Med Biol. 50: 309-316.

5. Khan FM (2003) The Physics of radiation therapy. 3rded. Philadelphia Lippincott Williams and wikins, Chapter 15: Brachytherapy: pp 357.

6. Hadadi A, Sadeghi M, Sardari D, Khanchi A, Shirazi A (2013) Monte Carlo characterization of biocompatible beta-emitting $90 \mathrm{Y}$ glass seed incorporated with the radionuclide $153 \mathrm{Sm}$ as a SPECT marker for brachytherapy applications. J Appl Clin Med Phys 14: 90-103.

7. Hosseini H, Sadeghi M, Ataeinia V (2009) Dosimetric comparison of four new 
Citation: Sadeghi M, Davoudi A, allaf MA, Jafari A (2018) Investigation of Dosimetric Parameters of HDR Cobalt-60 after-loading Brachytherapy Source using Monte Carlo Fluka Code. J Nucl Med Radiat Ther 9: 366. doi: 10.4172/2155-9619.1000366

design 103Pd brachytherapy sources: Optimal design using silver and copper rod cores. Med Phys. 36: 3080-3085.

8. Saidi P, Sadeghi M, Shirazi A, Tenreiro C (2011) Dosimetric parameters of the new design 103Pd brachytherapy source based on Monte Carlo study. Physica Medica 28: 13-18.

9. Saidi P, Sadeghi M, Shirazi A, Tenreiro C (2010) Monte Carlo calculation of dosimetry parameters for the IR08-103Pd brachytherapy source. Medical physics 37: 2509

10. Sahoo S, PalaniSelvam T, Vishwakarma R.S, Chourasiya G (2010) Monte Carlo modeling of ${ }^{60} \mathrm{Co}$ HDR brachytherapy source in water and in different solid water phantom materials. J Med Phys 35: 15-22.
11. Saidi P, Sadeghi M, Shirazi A, Tenreiro C (2010) Monte Carlo calculation of dosimetry parameters for the IR08-103Pd brachytherapy source. Medical physics 37: 2509

12. Ferrari A, Sala P.R, Fasso A, Ranft J (2005) FLUKA: a multi-particle transport code. CERN 2005-10 INFN/TC 05/11, SLAC-R-773.

13. Anjomrouz M, Sadeghi M, Haddadi A, Ferrari A, Sala P.R et al (2005) FLUKA a multi-particle transport code. CERN 2005-10 INFN/TC_05/11, SLAC-R-773 Monte Carlo characterization of $169 \mathrm{Yb}$ as a high-dose-rate source for brachytherapy application by FLUKA code. Journal of Applied Clinical Medical Physics, 14 X 196-205 